**POSTPRINT: Final manuscript after peer review and changes. Article published as: Green, H. J., Steinnagel, G., Morris, C., \& Laakso, E. L. (2014). Health behaviour models and patient preferences regarding nutrition and physical activity after breast or prostate cancer diagnosis. European Journal of Cancer Care, 23, 640-652. doi: 10.1111/ecc.12190**

\title{
Health behaviour models and patient preferences regarding nutrition and physical activity after breast or prostate cancer diagnosis
}

\author{
Heather J. Green ${ }^{1}$, Gabriella Steinnagel ${ }^{1,2}$, Collette Morris ${ }^{1,3}$, \& E-Liisa Laakso ${ }^{4}$ \\ Heather J. Green BSc(Hons), PhD, GCHEd: Lecturer \\ ${ }^{1}$ Griffith Health Institute Behavioural Basis of Health Program \& School of Applied \\ Psychology, Griffith University, Gold Coast, Australia \\ Email: H.Green@griffith.edu.au
}

Gabriella Steinnagel BPsych(Hons): Mental Health Housing Supporter

${ }^{2}$ City of Gothenburg, Sweden

Email: gsteinnagel@hotmail.com

Collette Morris BBus BPsychSc(Hons): Masters Candidate

${ }^{3}$ School of Psychology, The University of Queensland, Brisbane, Australia

Email: colsheba@ hotmail.com

E-Liisa Laakso BPhty(Hons), PhD, GCMgmt(QH): Associate Professor

${ }^{4}$ Griffith Health Institute Centre for Musculoskeletal Research \& School of Allied Health Sciences, Griffith University, Gold Coast, Australia

Email: L.Laakso@griffith.edu.au

\section{Running head: NUTRITION AND ACTIVITY AFTER CANCER DIAGNOSIS}

Correspondence should be addressed to: Dr Heather Green, School of Applied Psychology, Gold Coast campus, Griffith University Qld 4222, Australia

Email: H.Green@griffith.edu.au; Phone +61 75678 9086; Fax: +61 756788291 


\begin{abstract}
This study aimed to improve understanding of prostate and breast cancer survivors' physical activity and nutrition and the association of these behaviours with two models. The first model, the Commonsense Self-Regulation Model (CSM), addresses cognitive and emotional perceptions of illness whereas the Transtheoretical Model (TTM) focuses on stage of readiness to engage in a behaviour. Participants who had been diagnosed with either breast $(N=145)$ or prostate cancer $(N=92)$ completed measures of demographic and health information, illness representations, stage of change, self-efficacy, and preferences regarding health behaviour interventions. Health behaviours in the past seven days were measured via the International Physical Activity Questionnaire and concordance with national dietary guidelines. As hypothesised, TTM variables (stage of change and self-efficacy) demonstrated independent associations with physical activity and nutrition in regression analyses. CSM variables were not independently associated with absolute levels of health behaviours but both TTM and CSM variables were independently associated with self-reported changes in physical activity and nutrition following prostate or breast cancer diagnosis. Many participants reported high interest in receiving lifestyle interventions, particularly soon after diagnosis. Results supported application of the TTM and CSM models for strengthening behaviour change intentions and actions in breast and prostate cancer survivors.
\end{abstract}

KEYWORDS: Breast Cancer, Prostate Cancer, Exercise, Nutrition, Psychological, Supportive care 


\section{Introduction}

Many people who are diagnosed with cancer are interested in optimising their health via lifestyle behaviours. In Australia, as in many other developed countries, prostate cancer (PC) and breast cancer (BC) are the most prevalent cancer types in men and women, respectively (Australian Institute of Health and Welfare and Australasian Association of Cancer Registries, 2007). The relevance of health behaviours such as physical activity and nutrition to prevalence and management of both $\mathrm{BC}$ and $\mathrm{PC}$ has increasingly been supported by research. Healthy diet and exercise may reduce the risk of developing PC or BC (Kushi et $a l ., 2012)$ and lessen negative physical and psychological effects of cancer and cancer treatments (Hong et al., 2007, Jones and Demark-Wahnefried, 2006). Lifestyle factors may also affect risk of recurrence and cancer-specific mortality (Ogunleye and Holmes, 2009, Demark-Wahnefried and Moyad, 2007, Winzer et al., 2011).

Although direct evidence of change in cancer recurrence from physical activity interventions has yet to be demonstrated (Winzer et al., 2011), the benefits for improving physical and psychological health of cancer survivors are well established (Courneya, 2003, Courneya et al., 2003, Holmes et al., 2005, Hong et al., 2007, Jones and DemarkWahnefried, 2006). Exercise has been shown to improve cardiovascular fitness, muscle strength, range of motion, body composition, immunity, self-esteem, happiness, body image, quality of life, and overall survival as well as to reduce common symptoms such as fatigue, depression, anxiety, pain, nausea, and the risk of developing other chronic disease (Courneya, 2003, Doyle et al., 2006, Jones and Demark-Wahnefried, 2006, Norman et al., 2007, Ogunleye and Holmes, 2009).

There is a lack of definitive evidence regarding recommended diets for cancer survivors to optimise physical health and prevent recurrence and mortality (Norman et al., 2007) but there is a general consensus regarding the importance of an adequate fruit and 
vegetable intake for both BC and PC survivors (Demark-Wahnefried et al., 2007, Jones and Demark-Wahnefried, 2006, Kellen et al., 2009). The American Cancer Society (Doyle et al., 2006) suggests that cancer survivors should follow their national dietary guidelines for the general population as there is limited evidence for a causative relationship between specific foods and reduced cancer recurrence and survival.

Health behaviour theories can help to understand why individuals vary in patterns of nutrition and physical activity. Moreover, there is a demonstrated need to better integrate different health behaviour models and facilitate translation of research into clinical practice (Hagger, 2009). In the present study, potential predictors of health behaviours from two complementary and widely applied health models, the Commonsense Self-Regulation Model (CSM) (Leventhal et al., 1984) and the Transtheoretical Model (TTM) (Prochaska and DiClemente, 1983), were assessed for associations with measures of nutrition and physical activity and with changes in these behaviours after diagnosis with BC or PC. Data regarding applicability of these models for PC and BC survivors were complemented by patient preference information that had the potential to assist with translating findings into future clinical applications.

\section{Commonsense Self-Regulation Model}

The CSM suggests that an individual develops "illness representations", which are personalised cognitive and emotional perceptions regarding their health problem (Leventhal et al., 1984). These representations guide health behaviours and coping strategies.

Components of illness representations in the model include: illness identity (physical symptoms the person attributes to their illness); timeline acute/chronic (beliefs about the duration of the illness); timeline cyclical (perceived variability of symptoms over time); consequences (beliefs about severity of physical and social consequences of the illness); personal control (amount of control the individual believes they have over the illness); 
treatment control (belief in the ability of treatment to cure or control the illness); illness coherence (extent to which the individual believes they understand the illness); emotional representations (negative emotions felt towards the illness); and cause (factors that the individual believes caused the illness; Hagger and Orbell, 2003, Moss-Morris et al., 2002).

The CSM has not previously been used to explain nutrition or physical activity in PC survivors, but it has been found that higher personal and treatment control predicted increased fruit, vegetable, and fibre intake in BC survivors (Rabin and Pinto, 2006). Moreover, higher perceptions of a chronic timeline have been associated with higher fruit, vegetable, and fibre intake for patients with Type 2 diabetes (Searle et al., 2007). Lower emotional representations have been associated with higher adherence to dietary restrictions for patients with end-stage renal disease (O'Connor et al., 2008). Previous research has also shown that chronic timeline, personal control and treatment control were positively correlated with physical activity in patients with Type 2 diabetes (Searle et al., 2007). Thus, the CSM has shown promise for understanding health behaviours in relation to serious health conditions but has had relatively little application in relation to health behaviours of PC or BC survivors.

\section{Transtheoretical Model}

The TTM suggests that there are five dynamic stages that define an individual's motivational readiness to change or maintain a behaviour (Prochaska and DiClemente, 1983). The first stage is precontemplation, when there is no intention to change the behaviour. Contemplation is when there is serious consideration about changing the behaviour.

Preparation shows commitment to behaviour change in the near term. In the action stage, the behaviour is successfully modified. The maintenance stage begins when the new behaviour has been sustained for six months and become part of the individual's lifestyle (Marcus et al., 1992). Self-efficacy, defined as an individual's situation-specific confidence that he or she can engage in the specific healthy behaviour (Greene et al., 1999), is a significant moderating 
factor in determining an individual's progression through the TTM stages (Marcus et al., 1992). Some, but not all research that applies this model incorporates the additional components of decisional balance and processes of change (Armitage, 2009).

The TTM has received both support and criticism in the research literature. A recent overview noted that results do not universally support the notion of discrete stages and that evidence is strongest for a distinction between earlier "motivational" stages (precontemplation, contemplation, preparation) and later "volitional" stages (action, maintenance; Armitage, 2009). Notably, the TTM stages have been used successfully in explaining the adoption of diet and exercise behaviours in BC and PC survivors (DemarkWahnefried et al., 2007, Demark-Wahnefried et al., 2000, Segal-Isaacson and Wylie-Rosett, 1998).

\section{Preferences for Intervention}

Understanding patterns of health behaviours following cancer, including both behaviours and preferences of cancer survivors, can help with service planning such as identifying theoretically- and empirically-supported target variables for intervention, likely numbers of participants, and optimal timing and format of interventions. Previous research that assessed level of interest in dietary and exercise interventions has shown strong interest in such interventions among survivors of early stage PC or BC (Demark-Wahnefried et al., 2000).

\section{Overview of Present Study}

This study aimed to improve understanding of physical activity and nutrition and their predictors among participants previously diagnosed with either PC or BC. Based on research described above, Hypothesis One predicted that better adherence to recommended guidelines for physical activity and nutrition would be associated with CSM variables indicating perceptions of a more chronic timeline, higher personal control, higher treatment control, and 
lower emotional representations. Hypothesis Two predicted that more physical activity and better nutritional adherence would be associated with TTM variables representing higher stage of change and higher self-efficacy. Interest in interventions was assessed as an additional research question rather than as a specific hypothesis.

\section{Methods}

\section{Participants}

The eligibility criterion was previous diagnosis of PC or BC. Participants could be undergoing treatment or have concluded treatment. After approval by a university Human Research Ethics Committee, BC and PC support groups in South-East Queensland and Northern New South Wales, Australia, were contacted via telephone and email. Support groups that wished to offer participation to their members could choose an in-person visit to the group by researchers, surveys posted to the group, online participation, or a combination of these methods. Recruitment was supplemented by an email sent to university students and staff and flyers displayed in cancer organisations and health clinics. Ninety-two men with PC history and 145 women with BC history participated.

\section{Measures}

Primary outcome measures were physical activity, nutrition, and changes in these behaviours since diagnosis. Secondary outcome measures were interest and preferences regarding dietary and exercise interventions. Potential predictor variables were demographic and medical items and variables from the CSM and TTM models.

Physical Activity. A short form of the International Physical Activity Questionnaire (IPAQ; four items) was used to measure self-reported physical activity (Craig et al., 2003). Participants recorded how many days (from the last seven) they engaged in vigorous and moderate physical activity, walking and sitting. The average duration of each activity was also recorded. Responses were converted into metabolic equivalent (MET) minutes 
(Ainsworth et al., 2000, Craig et al., 2003). Test-retest reliability for the IPAQ short form has been reported as .75 (Craig et al., 2003). The IPAQ short form has demonstrated reliability and validity across at least 12 countries (Craig et al., 2003). It is regularly used as a public health measure of physical activity (Hagströmer et al., 2006, Rzewnicki et al., 2003).

Nutrition. Nutrition was assessed using the six-item "Past Seven Days Nutrition Measure", a measure developed by this study's authors based on the IPAQ format. Questions concerned how many portions of food from each of six food groups (cereals/grains; vegetables; fruit; dairy products; meat/legumes/nuts; and fats/oils/sugar) had been consumed each day on average in the past seven days. Questions and serving size examples were based on the "Australian Guidelines for Healthy Eating" (Kellett et al., 1998, National Health and Medical Research Council, 2003). Participants were assigned a total nutrition score of 0-6, which indicated how many of the age- and sex-specific healthy eating guidelines were adhered to in the past seven days.

Exercise and Diet Changes. Participants were asked to record the extent to which their diet and exercise behaviour had changed since diagnosis on a five point scale, with three representing have not changed. For example, for exercise 1=much less now, 2=a little less now, 3=have not changed, 4=a little more now, 5=a lot more now. There were also two open ended questions for participants to elaborate on their answers.

Preferences for Intervention. Three items created by Demark-Wahnefried and colleagues (Demark-Wahnefried et al., 2000) to measure interest in healthy lifestyle interventions for BC and PC survivors were used. Participants recorded interest in health interventions (e.g., health promotion programs and health related information with a diet and exercise focus) on a five point Likert scale ranging from $1=$ not at all interested to $5=$ extremely interested. Preferences for delivery modes of health interventions (e.g., mailed brochures, face-to-face) were recorded on the same five point Likert scale. Lastly, 
participants indicated preferences for the timing of health interventions (e.g., at diagnosis or soon after).

Illness Representations. The Illness Perception Questionnaire-Revised (IPQR) was designed to quantify the CSM illness representations (Moss-Morris et al., 2002). "Illness identity" was measured as the sum of 14 yes/no items regarding symptoms that the participant had experienced since diagnosis (e.g., fatigue, weight change) and which they attributed to their illness. Timeline acute/chronic, timeline cyclical, consequences, personal control, treatment control, illness coherence, and emotional representations were each measured on a five point Likert scale, ranging from 1=strongly disagree to 5=strongly agree . Answers to each set of items were summed, giving a total score for each illness representation. Cronbach's alpha for the subscales has been reported as .80 to.89 and construct validity has been demonstrated (Moss-Morris et al., 2002).

Exercise and Diet Stage of Change. Exercise stage of change was measured with a scale developed by Marcus et al. (1992). Each of the six items related to one stage of change (e.g., the maintenance item was "I currently exercise regularly and have done so for longer than six months"). Scale instructions defined regular exercise as three or more times per week for a minimum of 20 minutes at each time. Respondents recorded their answers on a five point Likert scale, ranging from 1=strongly disagree to 5=strongly agree. Stage of change was assigned as the stage for which agree or strongly agree was selected. If more than two stages were selected, the higher stage of change was assigned. Two-week test-retest reliability has been reported as $r=.90$ (Marcus et al., 1992). Sarkin, Johnson, Prochaska and Prochaska (2001) have confirmed concurrent validity with exercise frequency.

The present authors adapted this scale to also measure nutrition stages of change. The adaptation involved replacing "exercise" with "eating healthily" (e.g., the precontemplation item was "I currently do not eat healthily, and I do not intend to start eating healthily in the 
next six months"). Eating healthily was defined as "eating a diet high in protein, fibre, fruit and vegetables and low in fat and sugar". The six nutrition items used the same five-point response scale as the exercise items.

Self-Efficacy. The Exercise Self-efficacy Scale (Schwarzer and Renner, 2005) determined the individual's degree of certainty that they could exercise in the presence of five barriers (e.g., tiredness). The Nutrition Self-efficacy Scale (Schwarzer and Renner, 2005) measured participants' degree of certainty that they could eat healthily in the presence of five barriers (e.g., having to try several times until it works). Self-efficacy responses were recorded on a four point Likert scale, ranging from 1=very uncertain to $4=v e r y$ certain. Responses were summed. The scales' authors have reported Cronbach's alpha levels for the Nutrition and Exercise Self-Efficacy Scales as .87 and .88, respectively. Concurrent validity has been demonstrated between the Nutrition Self-Efficacy Scale and self-reported food intake (Schwarzer and Renner, 2005).

\section{Procedure}

Participants completed questionnaires electronically or via hard copy returned by reply-paid mail.

\section{Data Analysis}

After data screening, descriptive statistics for the two groups were compared using ttests and chi-square analysis for continuous and dichotomous variables, respectively. Correlations between predictor variables and outcome measures were calculated. Multiple regressions were used to calculate the relative associations of predictor variables with physical activity and nutrition outcomes, in terms of both adherence to guidelines and selfreported change in exercise and eating since diagnosis. Preferences regarding interventions were examined using frequency distributions. 


\section{Results}

\section{Data Screening, Participant Characteristics, and Preliminary Analyses}

When participants completed at least $50 \%$ of a scale, the score was prorated using the mean for completed items to estimate the most likely score if the missing items had been completed (Green et al., 2011, Morris and Coyle, 1994). "Unsure” IPAQ responses for duration of physical activity (32 cases; $14 \%$ ) were substituted with the relevant median session time (30 minutes for vigorous or moderate activity and 40 minutes for walking). There was a small amount of missing data (2-9\% of cases per variable). Unexpectedly, age was missing for 32 participants (22\% of $\mathrm{BC}$ and $0 \%$ of PC cases): on the $\mathrm{BC}$ questionnaire, age was the first item and responses appear to have been inadvertently omitted. Cases with missing data did not differ systematically from other cases. Analyses were conducted using cases with complete data for the specific analysis, to maximise statistical power.

The age range for PC participants was 45-84 years $(M=66.6, S D=7.7)$ and for BC participants 32-82 years $(M=56.8, S D=10.5)$. Average Body Mass Index (BMI) was 26.1 $(S D=3.1)$ and $26.3(S D=5.4)$ for $\mathrm{PC}$ and $\mathrm{BC}$, respectively. Elapsed time since diagnosis ranged from 2 to 190 months (PC), and 0 to 372 months (BC). Thirty-five percent of BC and $28 \%$ of PC participants were undergoing current cancer treatment, such as hormonal therapies. Further descriptive statistics are shown in Table 1. Comparisons showed several group differences: on average, BC participants were significantly younger, had longer time since diagnosis, were less likely to have a partner, and were more likely to have undergone treatments including chemotherapy, radiotherapy, surgery, and "other" treatments. In contrast, the groups were well matched for education, BMI, proportion receiving current treatment, and proportion who had received treatment for their cancer. 
Insert Table 1 about here

For both physical activity and nutrition, several participants reported "average" daily

values that were implausibly high. Some participants may have mistakenly reported cumulative activity or nutrition for seven days rather than a daily average. For physical activity, there were no discontinuities in the cumulative physical activity time reported, which ranged from 0 to 5,220 minutes in the past week, and it was therefore not possible to identify which participants may have made this recording error. Therefore, further analyses of physical activity used a dichotomised score, representing whether or not the participant reported activity in the past seven days that met current World Health Organization (WHO) recommendations of a minimum of 150 minutes of moderate physical activity per week (or 75 minutes of vigorous physical activity, or an equivalent combination of vigorous and moderate physical activity; World Health Organization, 2010). Several outlying nutrition scores suggested cumulative seven-day rather than average daily consumption (e.g., participants reporting consumption of 28 serves of fruit per day). Outlying scores were therefore divided by seven, which resulted in changing five PC nutrition scores (increases of one to two points on the six point nutrition scale).

Square root transformations corrected positive skew in illness identity, timeline cyclical, and treatment control. Log transformation corrected positive skew in time since diagnosis. Reflect and square root transformations corrected negative skew for exercise selfefficacy and consequences. A ceiling effect was found on both exercise and diet stages of change and as a result, these variables were dichotomised into action or maintenance stages compared to pre-action stages. This is considered the most meaningful theoretical distinction within the stage of change approach (Armitage, 2009). 


\section{Adherence to Health Behaviour Guidelines}

Descriptive statistics and correlations for predictor and outcome variables are shown in Table 2 . WHO physical activity recommendations were reportedly met by $88 \%$ of men and $85 \%$ of women. No participant followed all six healthy eating guidelines. On average, PC respondents met 2.2 of these guidelines ( $S D=1.0$, range $0-5)$ and $\mathrm{BC}$ respondents met 2.7 $(S D=1.0$, range 1-5).

Insert Table 2 about here

\section{Health Behaviour Change}

When asked if physical activity had changed after diagnosis, $41 \%$ of $\mathrm{BC}$ and $39 \%$ of PC participants reported increased exercise, $33 \%$ and $27 \%$ reported decreased exercise, and $26 \%$ and $34 \%$, respectively, indicated no change in exercise. The groups did not differ in proportions of participants reporting each trajectory of physical activity, $\chi^{2}(2)=1.67, p=.374$. Regarding diet changes since diagnosis, 59\% of BC and 59\% of PC participants reported eating more healthily, $6 \%$ of $\mathrm{BC}$ and no PC participants indicated eating less healthily, and $34 \%$ and $41 \%$, respectively, remained unchanged. Fisher's exact test showed that these group proportions differed significantly, test statistic $=6.28, p=.042$. Pairwise comparisons of PC and $\mathrm{BC}$ data using Bonferroni correction demonstrated that the overall difference in nutrition trajectories between the groups occurred because the proportion of participants reporting less healthy eating since diagnosis was significantly higher in the $\mathrm{BC}$ than $\mathrm{PC}$ group.

\section{Predictors of Physical Activity}

Adherence to Guidelines. Physical activity correlated significantly with higher exercise self-efficacy and exercise stage of change as well as with healthy eating, nutrition self-efficacy, and nutrition stage of change (see Table 2). There were no correlations with illness perception variables. Demographic, TTM activity, and illness perception predictors were entered into a logistic regression for physical activity (see Table 3). A test of the full 
model against a constant only model was statistically significant, indicating that the predictors as a set reliably distinguished between participants who did and did not meet physical activity guidelines in the past week $\left(\chi^{2}[14]=94.42, p<.001\right)$. Nagelkerke's $\mathrm{R}^{2}$ of .68 indicated a moderately strong relationship between prediction and grouping. Prediction success overall was $92 \%$ (97\% for sufficient and 64\% for insufficient physical activity).

The only two predictor variables that showed statistically significant independent associations with physical activity in the logistic regression according to the Wald test were exercise self-efficacy and exercise stage of change. Directions of these associations were consistent with correlations: higher self-efficacy and stage of change were associated with increased physical activity.

\section{Insert Table 3 about here}

\section{Self-Reported Change in Physical Activity. The same predictors as for adherence} were used to compute a multiple regression where the dependent variable was self-reported change in physical activity since diagnosis (see Table 4). The regression was significant, $F(14,175)=5.99, p<.001$, and accounted for a moderate amount of variance, $\mathrm{R}^{2}=.32$ (adjusted $\mathrm{R}^{2}=.27$ ). Increased exercise since diagnosis showed significant independent associations with diagnosis (higher for $\mathrm{BC} ; 2 \%$ of variance in exercise was accounted for by diagnosis as indicated by this predictor variable's partial semi-correlation $\left[s r^{2}\right]$ shown in Table 4); lower illness identity (3\% of variance); higher personal control (5\%); higher treatment control (2\%); and higher stage of change (11\%).

Insert Table 4 about here

\section{Predictors of Healthy Eating}

Adherence to Guidelines. The number of nutritional guidelines met correlated significantly with nutrition self-efficacy but not stage of change. Significant correlations were 
also found between greater adherence to guidelines and higher illness identity, lower personal control, and lower illness coherence. Standard multiple regression was conducted using demographic, TTM nutrition, and illness perception predictor variables. The model was statistically significant, $F(14,178)=2.41, p=.004$, but accounted for a relatively small proportion of variance, $\mathrm{R}^{2}=.16$ (adjusted $\mathrm{R}^{2}=.09$ ). As shown in Table 3 , statistically significant predictors that were independently associated with variance in adherence to nutritional guidelines according to the multiple regression analysis were university education, (accounting for $2 \%$ of variance in adherence); nutrition self-efficacy (2\%), and nutrition stage of change (2\%). In the regression, both higher self-efficacy and higher stage of change showed statistically significant independent associations with adherence to nutritional guidelines. Having a university education was associated with lower adherence to guidelines in multiple regression.

Self-Reported Change in Healthy Eating. Change in healthy eating showed an overall significant association with the predictors in multiple regression, $F(14,173)=3.64$, $p<.001, \mathrm{R}^{2}=.23$ (adjusted $\mathrm{R}^{2}=.17$ ). As shown in Table 4, healthier eating since diagnosis showed significant independent associations with longer time since diagnosis ( $2 \%$ of variance); higher personal control (8\%); higher negative emotional representations (3\%); and higher stage of change $(6 \%)$.

\section{Interest in Health Behaviour Intervention}

As shown in Table 5, a majority of participants in both groups indicated that they would be "very interested" or "extremely interested" in receiving interventions to assist them with improving nutrition or exercise. Preference was strongest for face-to-face interventions; mailed brochures, internet, and DVD formats each attracted moderate support; and telephone interventions received the lowest support. The most frequently endorsed timing for such interventions was "At diagnosis or soon after" but there was some support for all timings, 
including a large group of survivors who stated that "any time" after diagnosis could potentially be suitable. There were no statistically significant differences between PC and BC survivors in intervention preferences.

Insert Table 5 about here

\section{Discussion}

The current study applied the CSM and the TTM to assist in understanding parameters for designing health behaviour interventions to follow BC or PC diagnosis. Multivariate analyses showed that higher stage of change and higher self-efficacy from the TTM were independently associated with higher adherence to both physical activity and nutrition guidelines. CSM variables did not show an independent association with adherence. In contrast, self-reported changes in activity and nutrition after BC or PC diagnosis showed independent associations with both TTM and CSM variables. Interestingly, over $80 \%$ of both cancer survivor groups reported activity levels in the past seven days that accorded with WHO physical activity guidelines. Adherence to nutrition guidelines was not as high, with the PC group meeting 2.2/6 recommendations and the BC group 2.7/6 recommendations on average in the past seven days.

\section{Models of Health Behaviour}

Hypothesis One was not supported in relation to absolute levels of adherence. In multivariate analyses, no CSM variable was independently associated with adherence to guidelines. Unlike this study, previous research in other participant groups has found some associations between CSM variables and both diet and physical activity (Searle et al., 2007, O'Connor et al., 2008). Illness perceptions may be more salient for some medical conditions than others (e.g., diabetes and kidney disease requiring ongoing management, whereas the 
majority [68\%] of participants in the present study were not currently on active cancer treatment).

In relation to self-reported changes in physical activity and nutrition since diagnosis, however, Hypothesis One was partially supported. Self-reported increased exercise in the period following diagnosis was associated with lower illness identity, higher personal control and higher treatment control. Healthier eating since diagnosis was associated with higher personal control and greater emotional distress about cancer. Associations between higher personal and treatment control beliefs and improved health behaviours since diagnosis suggest that PC and BC survivors are more motivated to improve health behaviours if they believe their actions and other treatments can make a difference to their cancer outcome.

Higher illness identity as a marker of lower likelihood of increased physical activity after diagnosis suggests that ongoing symptoms attributed to cancer may act as a barrier to physical activity. On an open-ended item regarding how physical activity had changed since diagnosis, some participants reported exercising less since diagnosis due to factors such as reduced energy, loss of strength, physical pain, treatment side effects, or fatigue. BC or PC survivors who experience issues like these may benefit from targeted assistance with designing or adapting activities to suit their present circumstances. No such association was seen with change in healthy eating.

The unexpected association between a healthier post-diagnosis diet and higher negative emotions relating to cancer (instead of lower negative emotions as predicted by Hypothesis One) suggests that concern about cancer may also act to motivate lifestyle changes. In related domains, moderate levels of worry about cancer (rather than excessively low or high levels) have been found to predict cancer detection behaviours such as attending screening mammography (Andersen et al., 2003, Sutton et al., 1994). It may be that moderate 
distress about cancer can also help to motivate positive health behaviour changes, although such change may be temporary (Jones and Demark-Wahnefried, 2006).

Hypothesis Two regarding associations between TTM variables and adherence was supported. Associations with stage of change were consistent with findings of other studies that have examined physical activity (Barké and Nicholas, 1990, Fallon et al., 2005) or healthy eating (Campbell et al., 1994, Glanz et al., 1998). Higher self-efficacy was also uniquely associated with higher physical activity and healthy eating in multivariate analyses. Similar findings using comparable instruments have been demonstrated by Baldwin and Courneya (1997) and Rogers et al. (2005).

The majority of participants were classified in the action and maintenance stages of exercise change. This outcome was also found by Demark-Wahnefried et al. (2000) and Pinto et al. (2002). The levels of both exercise stage of change and self-reported physical activity were higher than would be expected in a general population sample, which has been found previously among cancer survivors (Jones and Demark-Wahnefried, 2006) but could also indicate self-selection of participants with a greater interest in healthy lifestyle behaviours than the general population of cancer survivors. Up to $15 \%$ of $\mathrm{BC}$ participants were recruited from the sporting group Dragons Abreast (a dragon boat paddling organisation for BC survivors; Dragons Abreast Australia, 2012) but physical activity levels were no higher among the $\mathrm{BC}$ than $\mathrm{PC}$ group.

Given that the stage of change measures incorporated behavioural as well as motivational information, it is of interest to compare results between the stage of change measures and their corresponding adherence measures. For both participant groups, $15-20 \%$ more participants were identified as meeting physical activity guidelines (86-88\% were meeting recommended guidelines) than were identified as being in action or maintenance stages of change for exercise. Approximately $40 \%$ of both participant groups reported 
increased physical activity post-diagnosis. In contrast, high proportions of both PC (90\%) and $\mathrm{BC}(81 \%)$ participants were identified as being in action or maintenance stages for healthy eating, and $59 \%$ of both groups said they were eating more healthily since diagnosis, yet on average participants were meeting only $37 \%$ and $45 \%$ of national nutritional recommendations, respectively. If the nutritional adherence measure was accurate, this finding suggests that many participants perceived themselves to be eating healthily although their overall adherence to guidelines was low. Given that motivation to eat healthily was high among this population, this suggests that it could be beneficial to provide more support for understanding and implementing recommended nutritional guidelines.

In most respects, the two participant groups reported similar health behaviours and changes. Exceptions to this were better nutritional adherence among BC participants, increased likelihood of worse nutrition following BC than PC diagnosis despite small proportions overall (6\% and $0 \%$, respectively), and greater likelihood of increased physical activity after BC diagnosis. Given that different types of cancer can have very different course, treatment, and prognosis, these results may or may not generalise to survivors of other types of cancer; this would need to be specifically assessed. The above results suggest that both participant groups may be interested in support for relevant health behaviours, and this was examined by asking about their level of interest and preferences for such interventions.

\section{Interest in Interventions}

The majority of both participant groups were very interested to extremely interested in diet and exercise health programs. Health behaviour interventions delivered face to face were the most preferred medium. Offering diet and exercise interventions at diagnosis or soon after and anytime were most preferred by both groups. Interventions should aim to fulfil these preferences in order to maximise convenience for PC or BC survivors, although noting that 
there was support for a range of intervention media and timings. Demark-Wahnefried et al. (2000) found similar results to the present study. Demark-Wahnefried, Pinto and Gritz (2006) suggested that interventions which provide education on appropriate energy balance, incorporating both diet and exercise aspects, are more likely to be effective than programs that focus on only one of these aspects.

\section{Limitations}

The main limitations were that all data were cross-sectional and obtained by self report. Therefore, causality cannot be inferred. A further caution in interpreting the physical activity data is that over reporting has been found previously with the IPAQ. For example, in a Belgian study involving telephone administration of the IPAQ, 56\% of respondents initially met the minimum physical activity recommendation. However after further probing, only $28 \%$ still met recommendations (Rzewnicki et al., 2003). Furthermore, it should be noted that the IPAQ was designed for adults aged 18 to 65 years (Craig et al., 2003). It may be that some older adults in the present study could have more accurately reported physical activity if they had been given a measure that was more specifically designed for their age range.

The use of customised measures to assess adherence to nutritional guidelines and nutrition stage of change (replacing "exercise" with "eating healthily") also needs to be taken into account when interpreting results. Subjective, self-rated dietary behaviour may not be an accurate perception of actual behaviour (Kristal et al., 2001, Lechner et al., 1998). Regarding BC survivors, a limited amount of research has been conducted on the relationship between diet stage of change and actual nutrition. However, Demark-Wahnefried et al. (2000) found that $76 \%$ of their BC survivor sample was currently in the action and maintenance stages of change of eating five portions of fruit and vegetables per day. 


\section{Conclusions and Future Directions}

Our results, which are largely consistent with previous research, support the idea of a "teachable moment" for promoting healthy behaviours following BC or PC diagnosis (Demark-Wahnefried et al., 2005). In particular, the results suggest that supporting personal control beliefs that provide a balanced viewpoint of potential benefits of optimal nutrition and activity may help to motivate healthier behaviours following diagnosis with BC or PC. Similarly, the independent association of self-efficacy with health behaviours suggests that health behaviour interventions following PC or BC diagnosis should incorporate techniques which foster exercise self-efficacy and healthy eating self-efficacy. This could be achieved by using a combination of behavioural education (e.g., time efficient exercise routines) and cognitive restructuring (e.g. confidence building, shaping positive attitudes towards health behaviours, overcoming automatic negative thoughts).

There appears to be a demand for health behaviour interventions with a physical activity and nutrition focus for survivors of BC or PC. The application of theoretical models to explain health behaviours can enhance our understanding and knowledge of how to provide effective support for cancer survivors. Results from this study support further efforts to understand the diverse behaviours and needs of cancer survivors; and towards developing appropriate screening methods in order to direct survivors of cancer to individually tailored lifestyle behaviour prescription. 


\section{References}

Ainsworth B. E., Haskell W. L., Whitt M. C., Irwin M. L., Swartz A. M., Strath S. J., O'Brien W. L., Bassett D. R., Jr, Schmitz K. H., Emplaincourt P. O., Jacobs D. R., Jr \& Leon A. S. (2000) Compendium of physical activities: An update of activity codes and MET intensities. Medicine and Science in Sports and Exercise 32, S498-S516.

Andersen M. R., Smith R., Meischke H., Bowen D. \& Urban N. (2003) Breast cancer worry and mammography use by women with and without a family history in a populationbased sample. Cancer Epidemiology, Biomarkers \& Prevention 12, 314-320.

Armitage C. J. (2009) Is there utility in the transtheoretical model? British Journal of Health Psychology 14, 195-210.

Australian Institute of Health and Welfare \& Australasian Association of Cancer Registries (2007) Cancer in Australia: An overview, 2006. Cancer series number 37, Catalogue number CAN 32. Australian Institute of Health and Welfare, Canberra, Australia.

Baldwin M. K. \& Courneya K. S. (1997) Exercise and self-esteem in breast cancer survivors: An application of the exercise and self-esteem model. Journal of Sport and Exercise Psychology 19, 347-358.

Barké C. R. \& Nicholas D. R. (1990) Physical activity in older adults: The stages of change. The Journal of Applied Gerontology 9, 216-223.

Campbell M. K., DeVellis B. M., Strecher V. J., Ammerman A. S., DeVellis R. F. \& Sandler R. S. (1994) Improving dietary behavior: the effectiveness of tailored messages in primary care settings. American Journal of Public Health 84, 783-787.

Courneya K. S. (2003) Exercise in cancer survivors: An overview of research. Medicine and Science in Sports and Exercise 35, 1846-1852.

Courneya K. S., Mackey J. R., Bell G. J., Jones L. W., Field C. J. \& Fairey A. S. (2003) Randomized controlled trial of exercise training in postmenopausal breast cancer survivors: Cardiopulmonary and quality of life outcomes. Journal of Clinical Oncology 21, 1660-1668.

Craig C. L., Marshall A. L., Sjöström M., Bauman A. E., Booth M. L., Ainsworth B. E., Pratt M., Ekelund U., Yngve A., Sallis J. F. \& Oja P. (2003) International physical activity questionnaire: 12-country reliability and validity. Medicine and Science in Sports and Exercise 35, 1381-1395.

Demark-Wahnefried W., Aziz N. M., Rowland J. H. \& Pinto B. M. (2005) Riding the crest of the teachable moment: Promoting long-term health after the diagnosis of cancer. Journal of Clinical Oncology 23, 5814-5830.

Demark-Wahnefried W., Clipp E. C., Lipkus I. M., Lobach D., Snyder D. C., Sloane R., Peterson B., Macri J. M., Rock C. L., McBride C. M. \& Kraus W. E. (2007) Main outcomes of the FRESH START trial: A sequentially tailored, diet and exercise mailed print intervention among breast and prostate cancer survivors. Journal of Clinical Oncology 25, 2709-2718.

Demark-Wahnefried W. \& Moyad M. M. (2007) Dietary intervention in the management of prostate cancer. Current Opinion in Urology 17, 168-174.

Demark-Wahnefried W., Peterson B., McBride C., Lipkus I. \& Clipp E. (2000) Current health behaviors and readiness to pursue life-style changes among men and women diagnosed with early stage prostate and breast carcinomas. Cancer 88, 674-684.

Demark-Wahnefried W., Pinto B. M. \& Gritz E. R. (2006) Promoting health and physical function among cancer survivors: Potential for prevention and questions that remain. Journal of Clinical Oncology 24, 5125-5131. 
Doyle C., Kushi L. H., Byers T., Courneya K. S., Demark-Wahnefried W., Grant B., McTiernan A., Rock C. L., Thompson C., Gansler T. \& Andrews K. S. (2006) Nutrition and physical activity during and after cancer treatment: An American Cancer Society guide for informed choices. CA: A Cancer Journal for Clinicians 56, 323-353.

Dragons Abreast Australia (2012). Who are we? Available from: http://www.dragonsabreast.com.au/Admin/who_are_we.htm (cited 2012).

Fallon E. A., Hausenblas H. A. \& Nigg C. R. (2005) The transtheoretical model and exercise adherence: examining construct associations in later stages of change. Psychology of Sport and Exercise 6, 629-641.

Glanz K., Kristal A. R., Tilley B. C. \& Hirst K. (1998) Psychosocial correlates of healthful diets among male auto workers. Cancer Epidemiology Biomarkers and Prevention 7 , 119-126.

Green H. J., Wells D. J. N. \& Laakso L. (2011) Coping in men with prostate cancer and their partners: a quantitative and qualitative study. European Journal of Cancer Care 20, 237-247.

Greene G. W., Rossi S. R., Rossi J. S., Velicer W. F., Fava J. L. \& Prochaska J. O. (1999) Dietary applications of the Stages of Change Model. Journal of the American Dietetic Association 99, 673-678.

Hagger M. S. (2009) Theoretical integration in health psychology: Unifying ideas and complementary explanations. British Journal of Health Psychology 14, 189-194.

Hagger M. S. \& Orbell S. (2003) A meta-analytic review of the common-sense model of illness representations. Psychology and Health 18, 141-184.

Hagströmer M., Oja P. \& Sjöström M. (2006) The International Physical Activity Questionnaire (IPAQ): a study of concurrent and construct validity. Public Health Nutrition 9, 755-762.

Holmes M. D., Chen W. Y., Feskanich D., Kroenke C. H. \& Colditz G. A. (2005) Physical activity and survival after breast cancer diagnosis. JAMA: The Journal of the American Medical Association 293, 2479-2486.

Hong S., Bardwell W., Natarajan L., Flatt S., Rock C., Newman V., Madlensky L., Mills P., Dimsdale J., Thomson C., Hajek R., Chilton J., Pierce J. \& the Women's Healthy Eating and Living (WHEL) Study Group (2007) Correlates of physical activity level in breast cancer survivors participating in the Women's Healthy Eating and Living (WHEL) Study. Breast Cancer Research and Treatment 101, 225-232.

Jones L. W. \& Demark-Wahnefried W. (2006) Diet, exercise, and complementary therapies after primary treatment for cancer. Lancet Oncology 7, 1017-1026.

Kellen E., Vansant G., Christiaens M.-R., Neven P. \& Van Limbergen E. (2009) Lifestyle changes and breast cancer prognosis: a review. Breast Cancer Research and Treatment 114, 13-22.

Kellett E., Smith A. \& Schmerlaib Y. (1998). The Australian guide to healthy eating. Available from: http://www.health.gov.au/internet/main/publishing.nsf/Content/F70AC8468184D729 CA257BF0001DE738/\$File/fd-cons.pdf (cited 1998).

Kristal A. R., Hedderson M. M., Patterson R. E. \& Neuhauser M. L. (2001) Predictors of selfinitiated, healthful dietary change. Journal of the American Dietetic Association 101, $762-766$.

Kushi L. H., Doyle C., McCullough M., Rock C. L., Demark-Wahnefried W., Bandera E. V., Gapstur S., Patel A. V., Andrews K., Gansler T., The American Cancer Society N. \& Physical Activity Guidelines Advisory C. (2012) American Cancer Society guidelines 
on nutrition and physical activity for cancer prevention. CA: A Cancer Journal for Clinicians 62, 30-67.

Lechner L., Brug J., De Vries H., van Assema P. \& Mudde A. (1998) Stages of change for fruit, vegetable and fat intake: consequences of misconception. Health Education Research 13, 1-11.

Leventhal H., Nerenz D. R. \& Steele D. J. (1984) Illness perceptions and coping with health threat. In: Handbook of psychology and health, Volume IV: social psychological aspects of health (eds. BAUM, A., TAYLOR, S. E. \& SINGER, J. E.), pp. 219-252. Erlbaum, Hillsdale, NJ.

Marcus B. H., Selby V. C., Niaura R. S. \& Rossi J. S. (1992) Self-efficacy and the stages of exercise behavior change. Research Quarterly for Exercise and Sport 63, 60-66.

Morris J. \& Coyle D. (1994) Quality-of-life questionnaires in cancer clinical trials: Imputing missing values. Psycho-Oncology 3, 215-222.

Moss-Morris R., Weinman J., Petrie K. J., Horne R., Cameron L. D. \& Buick D. (2002) The revised illness perception questionnaire (IPQ-R). Psychology and Health 17, 1-16.

National Health and Medical Research Council (2003) Dietary Guidelines for Australian Adults. National Health and Medical Research Council, Canberra, Australia.

Norman S. A., Potashnik S. L., Galantino M. L., De Michele A. M., House L. \& Localio A. R. (2007) Modifiable risk factors for breast cancer recurrence: what can we tell survivors? Journal of Women's Health 16, 177-190.

O'Connor S. M., Jardine A. G. \& Millar K. (2008) The prediction of self-care behaviors in end-stage renal disease patients using Leventhal's Self-Regulatory Model. Journal of Psychosomatic Research 65, 191-200.

Ogunleye A. A. \& Holmes M. D. (2009) Physical activity and breast cancer survival. Breast Cancer Research 11, 106.

Pinto B. M., Maruyama N. C., Clark M. M., Cruess D. G., Park E. \& Roberts M. (2002) Motivation to modify lifestyle risk behaviors in women treated for breast cancer. Mayo Clinic Proceedings 77, 122-129.

Prochaska J. O. \& DiClemente C. C. (1983) Stages and processes of self-change of smoking: Toward an integrative model of change. Journal of Consulting and Clinical Psychology 51, 390-395.

Rabin C. \& Pinto B. (2006) Cancer-related beliefs and health behavior change among breast cancer survivors and their first-degree relatives. Psycho-Oncology 15, 701-712.

Rogers L. Q., Shah P., Dunnington G., Greive A., Shanmugham A., Dawson B. \& Courneya K. S. (2005) Social cognitive theory and physical activity during breast cancer treatment. Oncology Nursing Forum 32, 807-815.

Rzewnicki R., Vanden Auweele Y. \& De Bourdeaudhuij I. (2003) Addressing overreporting on the International Physical Activity Questionnaire (IPAQ) telephone survey with a population sample. Public Health Nutrition 6, 299-305.

Sarkin J. A., Johnson S. S., Prochaska J. O. \& Prochaska J. M. (2001) Applying the Transtheoretical Model to regular moderate exercise in an overweight population: Validation of a stages of change measure. Preventive Medicine 33, 462-469.

Schwarzer R. \& Renner B. (2005). Health-specific self-efficacy scales. Available from: http://userpage.fu-berlin.de/ health/healself.pdf (cited 2005).

Searle A., Norman P., Thompson R. \& Vedhara K. (2007) Illness representations among patients with type 2 diabetes and their partners: Relationships with self-management behaviors. Journal of Psychosomatic Research 63, 175-184.

Segal-Isaacson C. \& Wylie-Rosett J. (1998) Weight and nutrition concerns in early-stage breast cancer. Topics in Clinical Nutrition 13, 70-78. 
Sutton S., Bickler G., Sancho-Aldridge J. \& Saidi G. (1994) Prospective study of predictors of attendance for breast screening in inner London. Journal of Epidemiology and Community Health 48, 65-73.

Winzer B., Whiteman D., Reeves M. \& Paratz J. (2011) Physical activity and cancer prevention: a systematic review of clinical trials. Cancer Causes and Control 1-16.

World Health Organization (2010). Global recommendations on physical activity for health. Available from: http://whqlibdoc.who.int/publications/2010/9789241599979_eng.pdf (cited 2010). 


\section{Table 1}

\section{Participant Demographic and Medical Characteristics}

\begin{tabular}{|c|c|c|c|}
\hline Variable & $\begin{array}{l}\text { Prostate Cancer } \\
\qquad(n=92)\end{array}$ & $\begin{array}{c}\text { Breast Cancer } \\
\quad(n=145)\end{array}$ & $\begin{array}{c}\text { Group } \\
\text { Comparison }\end{array}$ \\
\hline & $\underline{M(S D) \text { Range }}$ & $\underline{M(S D) \text { Range }}$ & $p$ \\
\hline \multirow[t]{2}{*}{ Age (years) } & $66.6(7.7) \quad 45-84$ & $56.8(10.5) 32-82$ & $<.001$ \\
\hline & $\underline{\operatorname{Median}(S D)}$ & $\underline{\operatorname{Median}(S D)}$ & \\
\hline Time since cancer diagnosis & $\underline{\text { Range }}$ & $\underline{\text { Range }}$ & \\
\hline \multirow[t]{2}{*}{ (months) } & $30.0(45.0) 2-190$ & $53.5(63.1) 0-372$ & .002 \\
\hline & $\underline{\%}$ & $\underline{\%}$ & \\
\hline Living with partner & 84 & 70 & .020 \\
\hline University Educated $^{\mathrm{a}}$ & 42 & 39 & .638 \\
\hline Currently in Cancer Treatment & 28 & 35 & .282 \\
\hline \multicolumn{4}{|l|}{ Previous treatment } \\
\hline Chemotherapy & 2 & 57 & $<.001$ \\
\hline Radiotherapy & 42 & 70 & $<.001$ \\
\hline Surgery & 48 & 96 & $<.001$ \\
\hline Other & 29 & 61 & $<.001$ \\
\hline No treatment received & 3 & 1 & .302 \\
\hline \multicolumn{4}{|c|}{${ }^{a}$ This was the most frequent response for the highest level of education completed. The oth } \\
\hline
\end{tabular}


Table 2.

Descriptive Statistics (Means, Standard Deviations and Percentages) and Correlations among Predictors and Criterion Variables

\begin{tabular}{|c|c|c|c|c|c|c|c|c|c|c|c|c|c|c|c|c|}
\hline Variable & $\mathrm{PC}$ & $\mathrm{BC}$ & $\begin{array}{c}\text { Group } \\
\text { Comparison } \\
p\end{array}$ & 2 & 3 & 4 & 5 & 6 & 7 & 8 & 9 & 10 & 11 & 12 & 13 & 14 \\
\hline $\begin{array}{l}\text { 1.Met exercise guidelines } \\
(0-1)\end{array}$ & $88 \%$ & $86 \%$ & .486 & $\begin{array}{l}.14 \\
(.039)\end{array}$ & $\begin{array}{l}-. .35 \\
(<.001)\end{array}$ & $\begin{array}{l}.14 \\
(.038)\end{array}$ & $\begin{array}{l}.51 \\
(<.001)\end{array}$ & $\begin{array}{l}.24 \\
(<.001)\end{array}$ & $\begin{array}{l}.01 \\
(.873)\end{array}$ & $\begin{array}{l}-.04 \\
(.525)\end{array}$ & $\begin{array}{l}-.00 \\
(.979)\end{array}$ & $\begin{array}{l}.11 \\
(.106)\end{array}$ & $\begin{array}{l}-.04 \\
(.582)\end{array}$ & $\begin{array}{l}.05 \\
(.461)\end{array}$ & $\begin{array}{l}-.01 \\
(.887)\end{array}$ & $\begin{array}{l}-.06 \\
(.397)\end{array}$ \\
\hline $\begin{array}{l}\text { 2.Met dietary guidelines } \\
(0-6)\end{array}$ & $2.2(1.0)$ & $2.7(1.0)$ & .001 & & $\begin{array}{l}-.02 \\
(.775)\end{array}$ & $\begin{array}{l}.15 \\
(.027)\end{array}$ & $\begin{array}{l}.12 \\
(.068)\end{array}$ & $\begin{array}{l}.12 \\
(.080)\end{array}$ & $\begin{array}{l}.16 \\
(.022)\end{array}$ & $\begin{array}{l}-.06 \\
(.377)\end{array}$ & $\begin{array}{l}.06 \\
(.349)\end{array}$ & $\begin{array}{l}-.00 \\
(.957)\end{array}$ & $\begin{array}{l}-.14 \\
(.034)\end{array}$ & $\begin{array}{l}-.11 \\
(.099)\end{array}$ & $\begin{array}{l}-.18 \\
(.008)\end{array}$ & $\begin{array}{l}-.00 \\
(.980)\end{array}$ \\
\hline $\begin{array}{l}\text { 3.Exercise self-efficacy } \\
(5-20)^{R, S}\end{array}$ & $15.7(3.4)$ & $14.6(4.0)$ & .043 & & & $\begin{array}{l}-.31 \\
(<.001)\end{array}$ & $\begin{array}{l}-.39 \\
(<.001)\end{array}$ & $\begin{array}{l}-.18 \\
(.007)\end{array}$ & $\begin{array}{l}.20 \\
(.003)\end{array}$ & $\begin{array}{l}-.02 \\
(.781)\end{array}$ & $\begin{array}{l}.11 \\
(.097)\end{array}$ & $\begin{array}{l}-.14 \\
(.039)\end{array}$ & $\begin{array}{l}-.11 \\
(.113)\end{array}$ & $\begin{array}{l}-.14 \\
(.045)\end{array}$ & $\begin{array}{l}-.17 \\
(.015)\end{array}$ & $\begin{array}{l}.22 \\
(.001)\end{array}$ \\
\hline $\begin{array}{l}\text { 4.Dietary self-efficacy } \\
(5-20)\end{array}$ & $16.1(3.1)$ & $15.6(4.2)$ & .259 & & & & $\begin{array}{l}.01 \\
(.921)\end{array}$ & $\begin{array}{l}.19 \\
(.006)\end{array}$ & $\begin{array}{l}.03 \\
(.688)\end{array}$ & $\begin{array}{l}-.01 \\
(.909)\end{array}$ & $\begin{array}{l}-.01 \\
(.893)\end{array}$ & $\begin{array}{l}.12 \\
(.074)\end{array}$ & $\begin{array}{l}.09 \\
(.192)\end{array}$ & $\begin{array}{l}.13 \\
(.058)\end{array}$ & $\begin{array}{l}.03 \\
(.684)\end{array}$ & $\begin{array}{l}-.15 \\
(.034)\end{array}$ \\
\hline $\begin{array}{l}\text { 5.Exercise Action or } \\
\text { Maintenance }\end{array}$ & $73 \%$ & $66 \%$ & .293 & & & & & $\begin{array}{l}.25 \\
(<.001)\end{array}$ & $\begin{array}{l}-.06 \\
(.369)\end{array}$ & $\begin{array}{l}.02 \\
(.816)\end{array}$ & $\begin{array}{l}-.08 \\
(.268)\end{array}$ & $\begin{array}{l}.09 \\
(.204)\end{array}$ & $\begin{array}{l}-.04 \\
(.568)\end{array}$ & $\begin{array}{l}.01 \\
(.942)\end{array}$ & $\begin{array}{l}.10 \\
(.163)\end{array}$ & $\begin{array}{l}-.08 \\
(.230)\end{array}$ \\
\hline $\begin{array}{l}\text { 6.Dietary Action or } \\
\text { Maintenance }\end{array}$ & $90 \%$ & $81 \%$ & .071 & & & & & & $\begin{array}{l}.09 \\
(.172)\end{array}$ & $\begin{array}{l}.10 \\
(.139)\end{array}$ & $\begin{array}{l}.05 \\
(.492)\end{array}$ & $\begin{array}{l}-.06 \\
(.386)\end{array}$ & $\begin{array}{l}-.04 \\
(.606)\end{array}$ & $\begin{array}{l}-.02 \\
(.787)\end{array}$ & $\begin{array}{l}.02 \\
(.807)\end{array}$ & $\begin{array}{l}-.03 \\
(.709)\end{array}$ \\
\hline 7.Identity ${ }^{\mathrm{S}}$ & $1.6(2.3)$ & $4.5(3.7)$ & $<.001$ & & & & & & & $\begin{array}{l}.12 \\
(.076)\end{array}$ & $\begin{array}{l}.44 \\
(<.001)\end{array}$ & $\begin{array}{l}-.40 \\
(<.001)\end{array}$ & $\begin{array}{l}-.18 \\
(.007)\end{array}$ & $\begin{array}{l}-.21 \\
(.002)\end{array}$ & $\begin{array}{l}-.29 \\
(<.001)\end{array}$ & $\begin{array}{l}.34 \\
(<.001)\end{array}$ \\
\hline 8.Chronic & $17.6(6.8)$ & $15.4(4.8)$ & .008 & & & & & & & & $\begin{array}{l}.28 \\
(<.001)\end{array}$ & $\begin{array}{l}-.25 \\
(<.001)\end{array}$ & $\begin{array}{l}-.06 \\
(.368)\end{array}$ & $\begin{array}{l}-.19 \\
(.006)\end{array}$ & $\begin{array}{l}.16 \\
(.019)\end{array}$ & $\begin{array}{l}.20 \\
(.004)\end{array}$ \\
\hline 9.Cyclical ${ }^{\mathrm{S}}$ & $8.2(3.8)$ & $9.5(3.8)$ & .013 & & & & & & & & & $\begin{array}{l}-.34 \\
(<.001)\end{array}$ & $\begin{array}{l}-.08 \\
(.249)\end{array}$ & $\begin{array}{l}-.17 \\
(.012)\end{array}$ & $\begin{array}{l}-.19 \\
(.005)\end{array}$ & $\begin{array}{l}.38 \\
(.000)\end{array}$ \\
\hline 10.Consequences ${ }^{R, S}$ & $18.5(5.8)$ & $18.7(4.1)$ & .703 & & & & & & & & & & $\begin{array}{l}.11 \\
(.097)\end{array}$ & $\begin{array}{l}.19 \\
(.004)\end{array}$ & $\begin{array}{l}.07 \\
(.305)\end{array}$ & $\begin{array}{l}-.39 \\
(<.001)\end{array}$ \\
\hline 11.Personal Control & $20.9(4.8)$ & $18.7(3.2)$ & $<.001$ & & & & & & & & & & & $\begin{array}{l}.39 \\
(<.001)\end{array}$ & $\begin{array}{l}.27 \\
(<.001)\end{array}$ & $\begin{array}{l}-.23 \\
(.001)\end{array}$ \\
\hline 12. Treatment Control ${ }^{\mathrm{S}}$ & $18.0(3.9)$ & $16.1(3.2)$ & .001 & & & & & & & & & & & & $\begin{array}{l}.55 \\
(<.001)\end{array}$ & $\begin{array}{l}-.14 \\
(.040)\end{array}$ \\
\hline 13.Illness Coherence & $20.6(3.6)$ & $14.4(4.9)$ & $<.001$ & & & & & & & & & & & & & $\begin{array}{l}-.08 \\
(.243)\end{array}$ \\
\hline 14.Emotional & $14.4(5.4)$ & $15.5(4.7)$ & .101 & & & & & & & & & & & & & \\
\hline
\end{tabular}

Note. ${ }^{R, S}=$ Reflect and square root transformation (changed direction of scoring). ${ }^{S}=$ Square root transformation (original direction of scoring). Where transformations were required, transformed variables were used to compute t-tests, chi-square and correlations. However, means and standard deviations are shown in raw score form for ease of interpretation and comparison with data from other studies. Below each correlation coefficient, the corresponding $p$ value is shown in parentheses. 
Table 3.

Multivariate Analyses of Adherence to Health Behaviour Guidelines

\begin{tabular}{|c|c|c|c|c|c|c|c|c|c|c|c|}
\hline \multirow[t]{2}{*}{ Variable } & \multicolumn{5}{|c|}{ Logistic Regression for Physical Activity } & \multicolumn{6}{|c|}{ Standard Multiple Regression for Healthy Eating } \\
\hline & $\mathrm{B}$ & $\mathrm{SE}(\mathrm{B})$ & $p$ & $e^{B}$ & $95 \%$ CI for $\mathrm{e}^{\mathrm{B}}$ & $\mathrm{B}$ & $\mathrm{SE}(\mathrm{B})$ & $\beta$ & $p$ & $\mathrm{sr}^{2}$ & $95 \% \mathrm{CI}$ for $\mathrm{B}$ \\
\hline Group & -0.68 & 1.12 & .541 & 0.51 & $0.06-4.51$ & 0.35 & 0.22 & .17 & .117 & .01 & $-0.09-0.80$ \\
\hline Time since diagnosis & -0.82 & 0.88 & .354 & 0.44 & $0.08-2.49$ & 0.28 & 0.19 & .12 & .134 & .01 & $-0.09-0.65$ \\
\hline Current treatment & -0.97 & 0.89 & .274 & 0.38 & $0.07-2.16$ & 0.09 & 0.16 & .04 & .578 & .00 & $-0.22-0.40$ \\
\hline Stage of change & 5.86 & 1.71 & .001 & 351.54 & $12.30-10044.05$ & 0.40 & 0.20 & .14 & .050 & .02 & $0.00-0.80$ \\
\hline Identity ${ }^{S}$ & 0.13 & 0.44 & .771 & 1.14 & $0.48-2.68$ & 0.05 & 0.09 & .06 & .578 & .00 & $-0.13-0.24$ \\
\hline Chronic & -0.08 & 0.08 & .283 & 0.92 & $0.79-1.07$ & -0.01 & 0.02 & -.04 & .611 & .00 & $-0.04-0.02$ \\
\hline Cyclical $^{\mathrm{S}}$ & 0.72 & 0.74 & .330 & 2.06 & $0.48-8.76$ & 0.07 & 0.14 & .04 & .629 & .00 & $-0.20-0.34$ \\
\hline Illness Coherence & -0.20 & 0.10 & .052 & 0.82 & $0.67-1.00$ & 0.01 & 0.02 & .03 & .794 & .00 & $-0.04-0.05$ \\
\hline Emotional Representations & -0.11 & 0.09 & .215 & 0.90 & $0.75-1.07$ & 0.02 & 0.02 & -.10 & .214 & .01 & $-0.06-0.01$ \\
\hline Constant & 3.58 & 5.50 & .515 & 35.90 & & 1.71 & 1.09 & & .118 & & $-0.44-3.87$ \\
\hline
\end{tabular}

Note. ${ }^{R, S}=$ Reflect and square root transformation (changed direction of scoring). ${ }^{S}=$ Square root transformation (original direction of scoring). 
Table 4.

Multiple Regressions for Self-Reported Changes in Health Behaviour After Cancer Diagnosis

\begin{tabular}{|c|c|c|c|c|c|c|c|c|c|c|c|c|}
\hline \multirow[t]{2}{*}{ Variable } & \multicolumn{6}{|c|}{ Exercise } & \multicolumn{6}{|c|}{ Healthy Eating } \\
\hline & B & SE(B) & $\beta$ & $p$ & $\mathrm{sr}^{2}$ & $95 \%$ CI for B & B & $\mathrm{SE}(\mathrm{B})$ & $\beta$ & $p$ & $\mathrm{sr}^{2}$ & $95 \%$ CI for B \\
\hline Group & 0.56 & 0.26 & .21 & .032 & .02 & $0.05-1.08$ & 0.08 & 0.19 & .04 & .685 & .00 & $-0.30-0.45$ \\
\hline University educated & 0.24 & 0.18 & .09 & .172 & .01 & $-0.11-0.59$ & 0.03 & 0.12 & .02 & .830 & .00 & $-0.22-0.27$ \\
\hline Time since diagnosis & 0.16 & 0.22 & .05 & .473 & .00 & $-0.27-0.58$ & 0.33 & 0.15 & .16 & .036 & .02 & $0.02-0.63$ \\
\hline Current treatment & 0.20 & 0.19 & .07 & .296 & .00 & $-0.17-0.57$ & 0.09 & 0.13 & .05 & .499 & .00 & $-0.17-0.35$ \\
\hline Self-efficacy ${ }^{R, S}$ exercise only & -0.19 & 0.11 & -.12 & .100 & .01 & $-0.41-0.04$ & 0.00 & 0.02 & .01 & .916 & .00 & $-0.03-0.03$ \\
\hline Stage of change & 1.03 & 0.19 & .36 & $<.001$ & .11 & $0.65-1.40$ & 0.61 & 0.17 & .25 & $<.001$ & .06 & $0.28-0.95$ \\
\hline Identity ${ }^{\mathrm{S}}$ & -0.31 & 0.11 & -.27 & .003 & .03 & $-0.52--0.11$ & -0.02 & 0.08 & -.03 & .759 & .00 & $-0.18-0.13$ \\
\hline Chronic & 0.01 & 0.02 & .05 & .521 & .00 & $-0.02-0.04$ & 0.02 & 0.01 & .16 & .051 & .02 & $0.00-0.05$ \\
\hline Cyclical $^{\mathrm{S}}$ & 0.11 & 0.16 & .05 & .481 & .00 & $-0.20-0.43$ & -0.09 & 0.11 & -.07 & .410 & .00 & $-0.32-0.13$ \\
\hline Consequences ${ }^{\mathrm{R}, \mathrm{S}}$ & -0.02 & 0.15 & -.01 & .887 & .00 & $-0.32-0.17$ & 0.06 & 0.11 & .05 & .557 & .00 & $-0.15-0.27$ \\
\hline Personal Control & 0.08 & 0.02 & .25 & .001 & .05 & $0.04-0.13$ & 0.07 & 0.02 & .33 & $<.001$ & .08 & $0.04-0.10$ \\
\hline Treatment Control $^{\mathrm{S}}$ & 0.65 & 0.26 & .21 & .014 & .02 & $0.13-1.16$ & -0.28 & 0.18 & -.14 & .127 & .01 & $-0.64-0.08$ \\
\hline Illness Coherence & -0.03 & 0.02 & -.12 & .229 & .00 & $-0.08-0.02$ & -0.00 & 0.02 & -.01 & .894 & .00 & $-0.04-0.03$ \\
\hline Emotional Representations & 0.04 & 0.02 & .13 & .083 & .01 & $-0.01-0.08$ & 0.04 & 0.01 & .20 & .012 & .04 & $0.01-0.06$ \\
\hline Constant & -2.69 & 1.30 & & .039 & & $-5.25--0.14$ & 1.55 & 0.90 & & .088 & & $-0.23-3.33$ \\
\hline
\end{tabular}

Note. ${ }^{R, S}=$ Reflect and square root transformation (changed direction of scoring). ${ }^{S}=$ Square root transformation (original direction of scoring). 


\section{Table 5}

Interest in Interventions, Modes of Delivery, and Preferred Time for Intervention after Breast or Prostate Cancer Diagnosis.

\begin{tabular}{|c|c|c|}
\hline Variable & Prostate Cancer & Breast Cancer \\
\hline & $\%$ very or extremely & $\%$ very or extremely \\
\hline General interest & interested & interested \\
\hline Nutrition intervention & $69 \%$ & $65 \%$ \\
\hline Physical activity intervention & $57 \%$ & $61 \%$ \\
\hline \multicolumn{3}{|l|}{ Mode of delivery } \\
\hline Face-to-face & $57 \%$ & $51 \%$ \\
\hline Mailed brochures & $34 \%$ & $42 \%$ \\
\hline Internet & $32 \%$ & $33 \%$ \\
\hline DVD & $32 \%$ & $30 \%$ \\
\hline Telephone & $15 \%$ & $19 \%$ \\
\hline \multicolumn{3}{|l|}{ Preferred time for intervention ${ }^{a}$} \\
\hline At diagnosis or soon after & $58 \%$ & $49 \%$ \\
\hline 3-6 months after diagnosis & $20 \%$ & $28 \%$ \\
\hline 7-11 months after diagnosis & $8 \%$ & $12 \%$ \\
\hline 1-2 years after diagnosis & $7 \%$ & $12 \%$ \\
\hline $\begin{array}{l}\text { More than } 2 \text { years after } \\
\text { diagnosis }\end{array}$ & $8 \%$ & $3 \%$ \\
\hline Any time & $47 \%$ & $40 \%$ \\
\hline
\end{tabular}

${ }^{a}$ Participants were given the option to select more than one response 